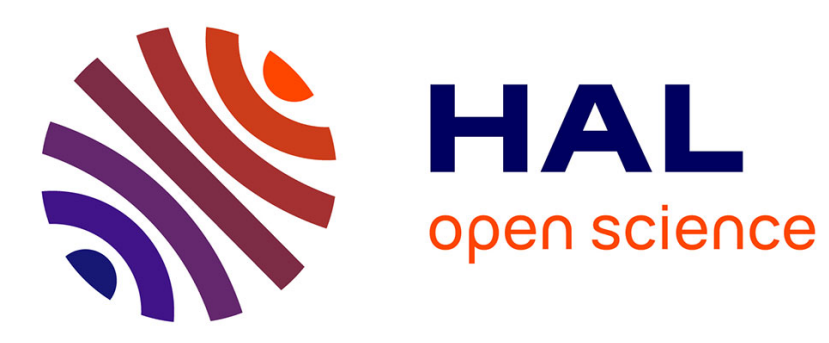

\title{
3D Analytical Calculation of Forces between Linear Halbach-Type Permanent Magnet Arrays
}

\author{
Hicham Allag, Jean-Paul Yonnet, Mohamed E. H. Latreche
}

\section{To cite this version:}

Hicham Allag, Jean-Paul Yonnet, Mohamed E. H. Latreche. 3D Analytical Calculation of Forces between Linear Halbach-Type Permanent Magnet Arrays. ELECTROMOTION, Jul 2009, Lille, France. hal-00402515

\section{HAL Id: hal-00402515 https://hal.science/hal-00402515}

Submitted on 7 Jul 2009

HAL is a multi-disciplinary open access archive for the deposit and dissemination of scientific research documents, whether they are published or not. The documents may come from teaching and research institutions in France or abroad, or from public or private research centers.
L'archive ouverte pluridisciplinaire HAL, est destinée au dépôt et à la diffusion de documents scientifiques de niveau recherche, publiés ou non, émanant des établissements d'enseignement et de recherche français ou étrangers, des laboratoires publics ou privés. 


\title{
3D Analytical Calculation of Forces between Linear Halbach-Type Permanent Magnet Arrays
}

\author{
H. Allag ${ }^{1,2}$, J-P. Yonnet ${ }^{1}$ and M. E. H. Latreche ${ }^{2}$ \\ 1- Laboratoire de Génie Electrique de Grenoble, G2E Lab (UMR 5269 CNRS/INPG-UJF), \\ Institut Polytechnique de Grenoble, ENSE3, BP46, St Martin d'Hères cedex, France \\ 2- Université de Constantine, Labo. L.E.C., Dept. d'Electrotechnique, 25000 Constantine, Algérie \\ Email: Hicham.Allag@g2elab.inpg.fr, Jean-Paul.Yonnet@grenoble-inp.fr
}

\begin{abstract}
Usely, in analytical calculation of magnetic and mechanical quantities of Halbach systems, the authors use the Fourier series approximation because the exact calculations are more difficult. In this work the interaction forces between linear Halbach arrays are analytically calculated thanks to our recent development 3D exact calculation of forces between two cuboïdal magnets with parallel and perpendicular magnetization. We essentially describe the way to separately calculate the forces between two magnets, between one magnet and a Halbach array and between two Halbach systems
\end{abstract}

Keywords - Halbach array, Permanent magnet, Magnetic Forces

\section{INTRODUCTION}

The analytical calculation is a very powerful and a very fast method to compute magnetic interactions. It is why the analytical expressions of all the interactions, energy, forces and torques between two cuboïdal magnets are very important results. Many problems can be solved by the addition of element interactions. The simpler shape of elementary volume is the parallelepiped, with its cuboïdal volume. It is why many $3 \mathrm{D}$ calculations can be made by the way of $3 \mathrm{D}$ interactions between two elementary magnets of cuboïdal shape. Up to now, only the force components between two magnets with the magnetization direction parallel to one edge of the parallelepipeds have been analytically solved. We have succeeded in a new result of first importance for the analytical calculation: the force when the magnetization directions are perpendicular. Consequently, by combining parallel and perpendicular magnetization directions, the analytical expressions can be written for any magnetization direction. Thanks to all this new result, the interaction energy and all the components of the forces can be calculated by fully analytical expressions, for any magnetization direction, and for any relative position between the two magnets.

The only two hypotheses are that the magnets own a cuboïdal shape, and they are uniformly magnetized. These results are very interesting to understand the mechanical forces acting on permanent magnets. For those reasons we are interesting in Halbach permanent magnet. The Halbach array is a special array of high-field permanent magnets in which the orientation of the magnetic poles of each magnet in the array has the unique property of producing a strong periodic magnetic field on one side of the array with a minimal field on the opposite side of the array. The Halbach array has been applied in particle accelerators or wigglers, magnet bearings [12], electrical machines $[1,2,7,8]$, and Maglev designs (Indutrack method) $[3,4,6]$.

For example, wigglers can be build using permanent magnets or electromagnets. Permanent magnet wigglers are made using rare-earth materials such as $\mathrm{SmCo}$ or $\mathrm{NdFeB}$. There magnet configurations is often referred to as the Halbach configuration [5].

\section{ANALYTICAL CALCULATION BACKGROUND}

Since the discovery and the development of Samarium Cobalt magnets in the 70 years and recently the development of rare-earth materials such as $\mathrm{SmCo}$ or $\mathrm{NdFeB}$, the designers can use magnets owning a really rigid magnetization. They are the magnets which can be used in repulsion without any risk of demagnetization. Their magnetization can be easily modelled by magnetic charges on the poles, or by equivalent currents. One of the first applications of Samarium Cobalt magnets were the magnetic bearings. Due to the circular symmetry, the calculation can be made in 2D. The first $2 \mathrm{D}$ analytical expressions of the forces between magnets were given by Marina Marinescu [9] and Jean-Paul Yonnet [10]. The stiffness of a magnetic bearing can be easily calculated by analytical expressions [11]. The magnetic couplings are another application working by interaction forces between permanent magnets. When their length is long in comparison with the airgap dimensions, the 2D analytical calculation can be used [12]. Otherwise it is necessary to use $3 \mathrm{D}$ calculation. The $3 \mathrm{D}$ analytical calculation is obviously more difficult than the $2 \mathrm{D}$. It is not 2 but 4 successive analytical integrations which must be calculated, and the difficulty fastly increases with the number of integrations. Many persons thought that the last analytical integration was not possible, and must be made by a numerical way. We had worked on this problem, and we have succeeded in solving the calculation. At that time all the integrations had been made by brain-work, with a pen and a piece of paper.

The first 3D forces analytical expressions were published in 1984 by Gilles Akoun and Jean-Paul Yonnet [13]. The forces were analytically calculated for two cuboïdal magnets with 
parallel magnetization directions. The calculus was made by the way of interaction energy determination. The forces expressions were obtained by derivation of the energy expression. Until now, all the analytical force calculation has been made for cuboïdal magnets which magnetization is parallel to one of the edge of the magnet. It means that the magnetic poles are only on two rectangular faces of the magnet [14]. Recently, we have worked again on the 1984 formulations, and we succeed in the analytical interaction energy calculation when the magnetization directions of the two cuboïdal magnets are perpendicular. From the expression of energy, the forces can be easily calculated by derivation. It is an important step, because its opens the way to the calculation of the interactions when the magnetization directions are in every direction. This result will be used easily for linear Halbach array magnetic field and forces calculations which have been studied until now, using different approaches.

\section{THE BASIC MATHEMATICAL MODEL}

\section{A. Magnetic induction created by a magnet}

Let us consider a rectangular surface $2 \mathrm{a} \times 2 \mathrm{~b}$, wearing a uniform pole density $\sigma$ (Fig. 1). We will calculate the scalar potential in the point $\mathrm{P}$, which coordinates are $(\mathrm{X}, \mathrm{Y}, \mathrm{Z})$.

The scalar potential $\mathrm{V}$ is given by:

$$
V=\frac{1}{4 \pi \mu_{0}} \iint_{S} \frac{\sigma \cdot d S}{\left\|\vec{r}-\vec{r}^{\prime}\right\|}
$$

By using the cartesian coordonates, it is equivalent to:

$$
V=\frac{\sigma}{4 \pi \mu_{0}} \int_{-b}^{b} d y^{\prime} \int_{-a}^{a} \frac{1}{\sqrt{\left(x^{\prime}-x\right)^{2}+\left(y^{\prime}-y\right)^{2}+z^{2}}} d x^{\prime}
$$

After two analytical integrations, we obtain:

$$
V=\frac{\sigma}{4 \pi \mu_{0}} \sum_{i=0}^{1} \sum_{j=0}^{1}(-1)^{i+j} \phi(U i, V j, W)
$$

The function $\phi$ is given by:

$$
\phi(U, V, W, r)=-U \ln (r-V)-V \ln (r-U)-W \cdot \operatorname{tg}^{-1}\left(\frac{U V}{r W}\right)
$$

Intermediary variables are:

$$
\begin{aligned}
& U_{i}=x-(-1)^{i} a, \quad V_{j}=y-(-1)^{j} b \text { and } W=z \\
& r=\sqrt{U_{i}^{2}+V_{j}^{2}+W^{2}}
\end{aligned}
$$

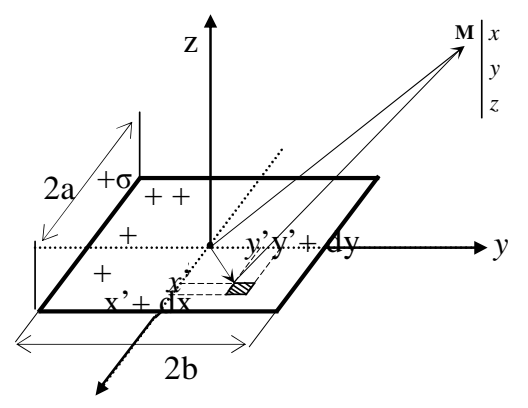

Figure 1 - Geometrical disposition for the potential and the field calculation
From the analytical expression of the scalar potential, the magnetic field $\mathrm{H}$ can be easily calculated by derivation. $H=-\operatorname{gra} d(V)$, it can be expressed as:

$$
\begin{gathered}
H=\frac{\sigma^{\prime}}{4 \pi \mu_{0}} \sum_{i=0}^{1} \sum_{j=0}^{1}(-1)^{i+j} \mathcal{E}(U i, V j, W) \\
\varepsilon_{x}=\ln (r-V) \quad \varepsilon_{y}=\ln (r-U) \quad \varepsilon_{z}=\operatorname{tg}^{-1}\left(\frac{U V}{W r}\right)
\end{gathered}
$$

By adding the field created by the two surfaces, we obtain the field created by a cuboïdal magnet (Fig. 2).

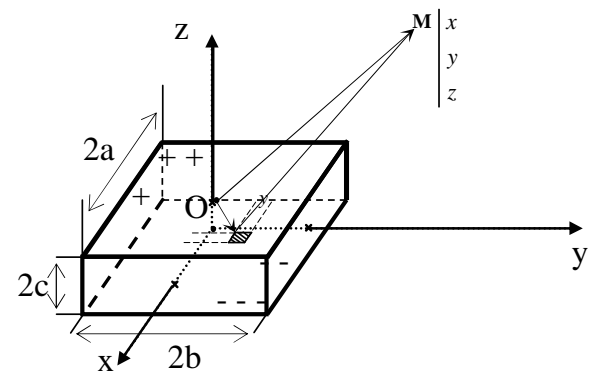

Figure 2 - Magnetic induction created by a magnet

The geometric parameters are shown on Fig. 2. Intermediary variables are:

$$
\begin{aligned}
U_{i}=x-(-1)^{i} a ; \quad V_{j} & =y-(-1)^{j} b \text { and } W_{k}=-(-1)^{k} c \\
r & =\sqrt{U_{i}^{2}+V_{j}^{2}+W_{k}^{2}}
\end{aligned}
$$

The magnetic field and induction components are given by :

$$
\begin{gathered}
H=\frac{\sigma}{4 \pi \mu_{0}} \sum_{k=0}^{1} \sum_{i=0}^{1} \sum_{j=0}^{1}(-1)^{i+j+k} \varepsilon\left(U_{i}, V_{j}, W_{k}\right) \\
B=\mu_{0} H=\frac{\sigma}{4 \pi} \sum_{k=0}^{1} \sum_{i=0}^{1} \sum_{j=0}^{1}(-1)^{i+j+k} \varepsilon\left(U_{i}, V_{j}, W_{k}\right)
\end{gathered}
$$

With $\mathcal{E}, \mathcal{E}_{x}, \mathcal{E}_{y}$ and $\mathcal{E}_{z}$ are the same in equation (6)

\section{B. Interaction energy calculation for parallel magnetization} directions

We study the interactions between two parallelepipedic magnets. Their edges are respectively parallel (Fig. 3). The magnetizations $\mathrm{J}$ and $\mathrm{J}$ ' are supposed to be rigid and uniform in each magnet. The dimensions of the first magnet are $2 \mathrm{a} \times 2 \mathrm{~b} \times$ $2 \mathrm{c}$, and its polarization is $\mathrm{J}$. Its center is $\mathrm{O}$, the origin of the axes Oxyz. For the second magnet, the dimensions are $2 \mathrm{~A} \times 2 \mathrm{~B}$ $\mathrm{x} 2 \mathrm{C}$, its polarization is $\mathrm{J}$ ', and the coordinates of its center $\mathrm{O}$ ' are $(\alpha, \beta, \gamma)$. The side $2 \mathrm{a}$ is parallel to the side $2 \mathrm{~A}$, and so on. The magnet dimensions are given on Table 1 .

\begin{tabular}{|l|l|l|l|}
\hline Axis & Ox & Oy & Oz \\
\hline First Magnet (J) & 2a & 2b & 2c \\
\hline Second Magnet (J') & 2A & 2B & 2C \\
\hline Second Magnet Position O' & $\alpha$ & $\beta$ & $\gamma$ \\
\hline
\end{tabular}

Table 1: Magnet dimensions and position

The magnetization directions shown on Figure 3 correspond to the case when the polarizations $\mathbf{J}$ and $\mathbf{J}$ ' have the same direction, parallel to the side $2 \mathrm{c}$. Note that the calculation stay valid when they are in opposite direction; only the expression sign is reversed. The polarizations $\mathbf{J}$ and $\mathbf{J}$ ' are supposed to be 
rigid and uniform. They can be replaced by distributions of magnetic charges on the poles. It is the coulombian representation of the magnetization.

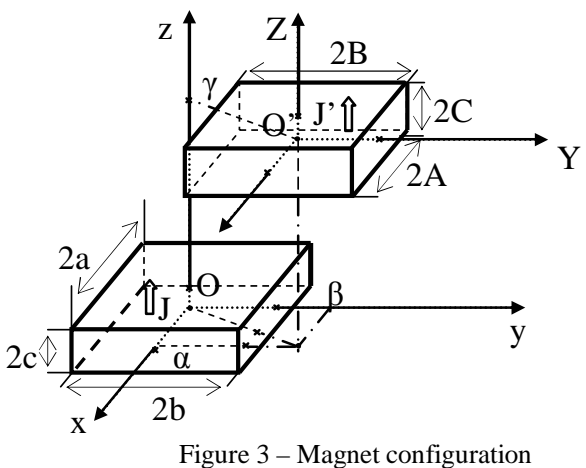

Their density $\sigma$ is defined by $\sigma=\vec{J} \cdot \vec{n}$. On the example of Figure 3 , since $J$ is perpendicular to the surfaces $2 \mathrm{a} \times 2 \mathrm{~b}$ and oriented to the top, these faces wear the density $\sigma=+\mathrm{J}$ on the upper face (North Pole), and $\sigma=-\mathrm{J}$ on the lower face (South Pole). All the analytical calculations have been made by successive integrals. We have determined the scalar potential created by one charged surface. From this scalar potential, the induction components can be obtained by derivation. For the whole magnets, we have calculated the interaction energy. The forces and the torques can be deduced by linear and angular derivation. The most difficult analytical calculation is the interaction energy in 3D. It is made by four successive integrations. The first one gives a logarithm function. In the second one, you have two logarithm and two arc-tangent functions. The last one owns many complex functions based on logarithm and arc-tangent functions. The interaction energy in a system of two magnets with parallel magnetization directions (Fig. 3) is given by:

$$
\begin{aligned}
& E=\frac{J . J^{\prime}}{4 \pi \mu_{0}} \sum_{p=0}^{1} \sum_{q=0}^{1}(-1)^{p+q} \int_{-C}^{C} d Y \int_{-A}^{A} d X \int_{-b}^{b} d y \int_{-a}^{a} \frac{1}{r} d x \\
& \text { with } \quad r=\sqrt{(\alpha+X-x)^{2}+(\beta+Y-y)^{2}+\left(\gamma+(-1)^{l} C-(-1)^{p} c\right)^{2}}
\end{aligned}
$$

The obtained expressions of the interaction energy are:

$$
E=\frac{J \cdot J^{\prime}}{4 \pi \mu} \sum_{i=0}^{1} \sum_{j=0}^{1} \sum_{k=0}^{1} \sum_{l=0}^{1} \sum_{p=0}^{1} \sum_{q=0}^{1}(-1)^{i+j+k+l+p+q} . \psi\left(U_{i j}, V_{k l}, W_{p q}, r\right)
$$

with

$$
\begin{aligned}
\psi(U, V, W, r)= & \frac{U\left(V^{2}-W^{2}\right)}{2} \ln (r-U)+\frac{V\left(U^{2}-W^{2}\right)}{2} \ln (r-V) \\
& +U V W \cdot \operatorname{tg}^{-1}\left(\frac{U V}{r W}\right)+\frac{r}{6}\left(U^{2}+V^{2}-2 W^{2}\right)
\end{aligned}
$$

The secondary variables are:

$$
\begin{aligned}
& U_{i j}=\alpha+(-1)^{j} A-(-1)^{i} a \\
& V_{k l}=\beta+(-1)^{l} B-(-1)^{k} b \\
& W_{p q}=\gamma+(-1)^{q} C-(-1)^{p} c
\end{aligned}
$$

with $r=\sqrt{U_{i j}^{2}+V_{k l}^{2}+W_{p q}^{2}}$

From the interaction energy, the force components can be obtained by $\vec{F}=-\operatorname{gra} d E$. Consequently the force components are:

$$
F=\frac{J \cdot J^{\prime}}{4 \pi \mu_{0}} \sum_{i=0}^{1} \sum_{j=0}^{1} \sum_{k=0}^{1} \sum_{l=0}^{1} \sum_{p=0}^{1} \sum_{q=0}^{1}(-1)^{i+j+k+l+p+q} . \phi\left(U_{i j}, V_{k l}, W_{p q}, r\right)
$$

with

$$
\begin{aligned}
& \phi_{x}(U, V, W, r)=\frac{\left(V^{2}-W^{2}\right)}{2} \ln (r-U)+U V \ln (r-V)+V W \cdot \operatorname{tg}^{-1}\left(\frac{U V}{W \cdot r}\right)+\frac{1}{2} U \cdot r \\
& \phi_{y}(U, V, W, r)=\frac{\left(U^{2}-W^{2}\right)}{2} \ln (r-V)+U V \ln (r-U)+U W \cdot \operatorname{tg}^{-1}\left(\frac{U V}{W \cdot r}\right)+\frac{1}{2} V \cdot r \\
& \phi_{z}(U, V, W, r)=-U W \ln (r-U)-V W \ln (r-V)+U W \cdot \operatorname{tg}^{-1}\left(\frac{U V}{W \cdot r}\right)-W \cdot r
\end{aligned}
$$

\section{Interaction energy calculation for perpendicular} magnetization directions

With applying the same procedure to magnets with perpendicular magnetization Fig. 4, we obtain for energy:

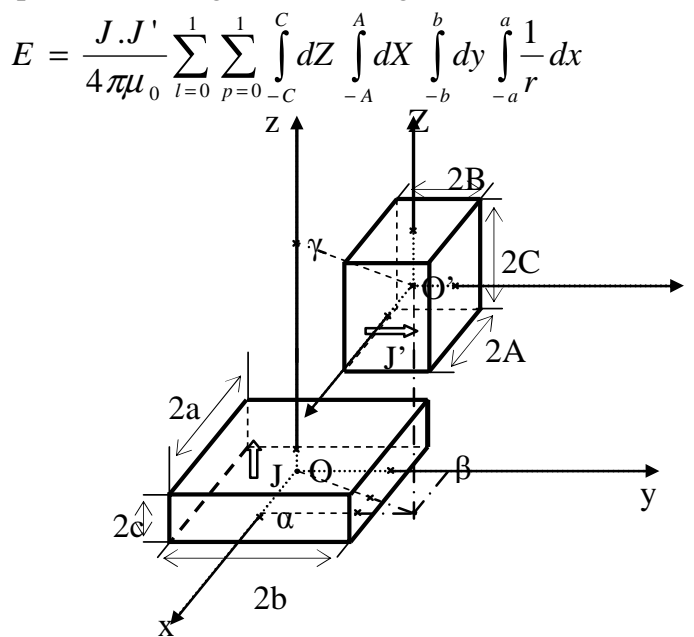

Figure 4 - Magnet configuration with perpendicular magnetization direction

The obtained expressions of the interaction energy are:

$$
E=\frac{J \cdot J^{\prime}}{4 \pi \mu_{6}} \sum_{i=0}^{1} \sum_{j=0}^{1} \sum_{k=0}^{1} \sum_{l=0}^{1} \sum_{p=0}^{1} \sum_{q=0}^{1}(-1)^{i+j+k+l+p+q} . \psi\left(U_{i j}, V_{k l}, W_{p q}, r\right)(16)
$$

with

$$
\begin{aligned}
\psi(U, V, W, r)= & \frac{V\left(V^{2}-3 U^{2}\right)}{6} \ln (W+r)+\frac{W\left(W^{2}-3 U^{2}\right)}{6} \ln (V+r) \\
& +\frac{U}{6}\left(3 V^{2} \operatorname{tg}^{-1}\left(\frac{U W}{V \cdot r}\right)+3 W^{2} \operatorname{tg}^{-1}\left(\frac{U V}{W \cdot r}\right)+U^{2} \operatorname{tg}^{-1}\left(\frac{V W}{U \cdot r}\right)\right) \\
& +U V W \cdot \ln (-U+r)+\frac{V \cdot W \cdot r}{3}
\end{aligned}
$$

The variables $U, V, W, r$ are the same than (Equation (13)) From the gradient of energy the force components are:

$$
F=\frac{J \cdot J^{\prime}}{4 \pi \mu_{b}} \sum_{i=0}^{1} \sum_{j=0}^{1} \sum_{k=0}^{1} \sum_{l=0}^{1} \sum_{p=0}^{1} \sum_{q=0}^{1}(-1)^{i+j+k+l+p+q} . \phi\left(U_{i j}, V_{k l}, W_{p q}, r\right)(18)
$$

$$
\text { with }
$$

$$
\begin{array}{r}
\phi_{x}(U, V, W, r)=-V W \ln (r-U)+V U \ln (r+W)+W U \ln (r+V) \\
\quad-\frac{U^{2}}{2} \operatorname{tg}^{-1}\left(\frac{V W}{U \cdot r}\right)-\frac{V^{2}}{2} \operatorname{tg}^{-1}\left(\frac{U W}{V \cdot r}\right)-\frac{W^{2}}{2} \operatorname{tg}^{-1}\left(\frac{U V}{W \cdot r}\right) \\
\phi_{y}(U, V, W, r)=\frac{\left(U^{2}-V^{2}\right)}{2} \ln (r+W)-U W \ln (r-U)-U V \cdot \operatorname{tg}^{-1}\left(\frac{U W}{V \cdot r}\right)-\frac{1}{2} W \cdot r \\
\phi_{z}(U, V, W, r)=\frac{\left(U^{2}-W^{2}\right)}{2} \ln (r+V)-U V \ln (r-U)-U W \cdot \operatorname{tg}^{-1}\left(\frac{U V}{W \cdot r}\right)-\frac{1}{2} V \cdot r
\end{array}
$$




\section{VALIDATION WITH FINITE ELEMENT METHOD}

In order to validate our analytical model, we chose two magnets which dimensions are presented in Fig. $5:$ two cubes of $1 \mathrm{~cm}$ edge, at a distance of $1 \mathrm{~cm}$.

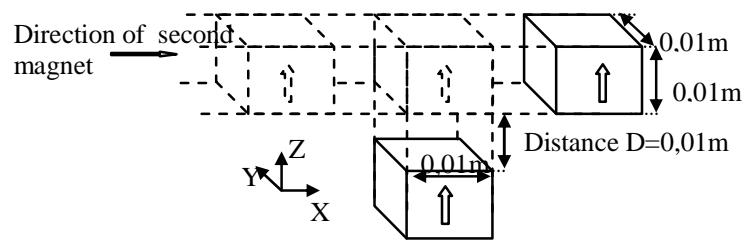

Figure 5 - Geometrical disposition of the magnets

Using 3D scalar magnetic potential finite element method for equal values of magnetization (1T for each permanent magnet), we obtain the potential from Flux3D ${ }^{\circledR}$ such as presented in Fig.6

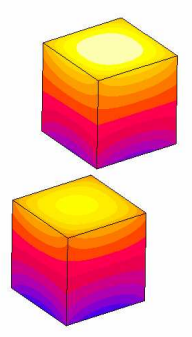

$\sum_{x}^{z}$

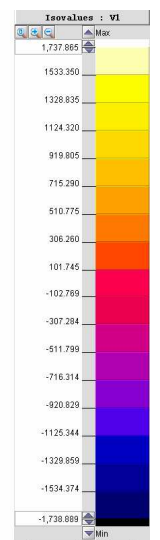

Figure 6 - Scalar potential presented for the two magnets

The three forces components are calculated by the two models - analytical and by FEM- and presented in Fig. 7. The upper magnet moves in translation along the $\mathrm{Ox}$ axis above the lower fixed magnet. The distance between the two magnets (airgap when the upper magnet is above the fixed magnet) is $10 \mathrm{~mm}$ (Fig. 5).

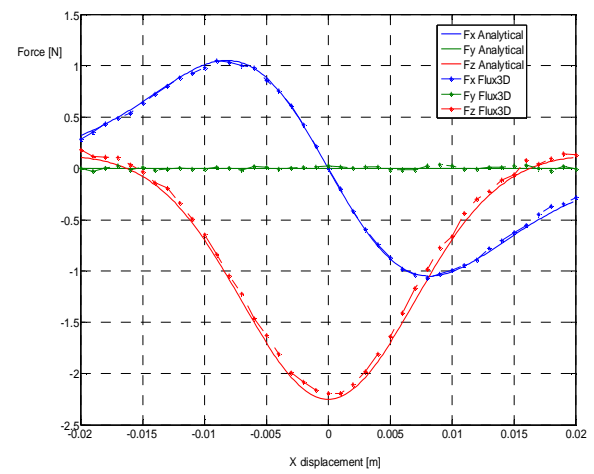

Figure 7 - Three force components calculated from analytical model and finite element method
From the last results, we remark the great resemblance of curves, but the analytical method presents some others advantages resumed in the facility of implementation and the rapidity of execution - 1minut for the analytical model versus 20 minuts for the FEM, for this example-.

\section{HALBACH MAGNET SYSTEM STUDY}

The ideal linear Halbach array has pure sinus magnetic profile, on the enhanced side of the array, while canceling the field on the other side [2]. Figure 8.a illustrates an ideal Halbach array, but it is impractical to fabricate. Instead, an array of rectangular or square permanent magnets (PM) is actually used. The practical (non-ideal) four- and eight-piece Halbach arrays are shown respectively in Fig. 8.b and Fig. 8.c. These non-ideal Halbach arrays are not able to provide the zero magnetic fields on the cancelled side and the purely sinusoidal magnetic field on the enhanced side. However, they still provide better performance characteristics than simply using an array composed of alternating polarity magnets.

a)

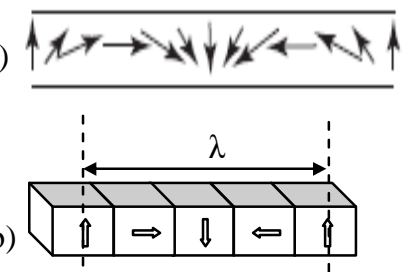

c)

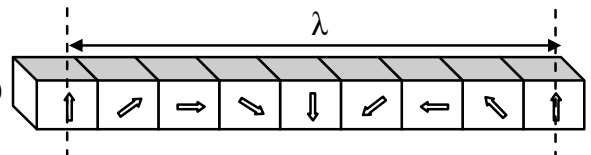

Figure 8 - Linear Halbach arrays permanent magnets configurations

For presenting the manner of interaction force calculation, let us considering a system composed of two eight-piece Halbach arrays Fig. 9, designed for a wiggler.

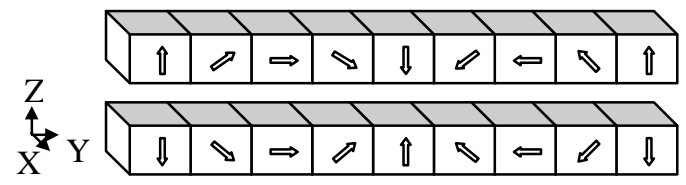

Figure 9 - Eight-piece Halbach wiggler system

By applying our model and superposition after, we can treat the problem at three essential cases, as follow:

\section{A. Parallel case}

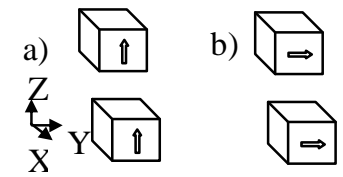

Figure 10 - Parallel case configuration

For the first parallel case Fig. 10.a the forces component are given from the equation (14). The same results are obtained for the second configuration Fig. $10 . \mathrm{b}$ with considering the following permutations $\left(\mathrm{V} \rightarrow \mathrm{W}\right.$ equation (13)) and $\left(\mathrm{F}_{\mathrm{y} \rightarrow \mathrm{F}_{\mathrm{z}}}\right.$ equation (14)) 


\section{B. Perpendicular case}

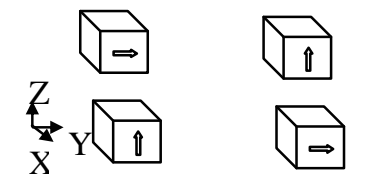

Figure 11- Parallel case configuration

In perpendicular case, the final expressions of force are similar - see equation (18)- by considering simply the following changing in axis $(\mathrm{V} \rightarrow \mathrm{W}$ and $\mathrm{W} \rightarrow-\mathrm{V})$

\section{Inclined case}

When one of the two magnetization directions is inclined Fig.12, it can be decomposed as the sum of parallel and perpendicular case. The whole energy and the forces can be calculated by addition of the interactions between the magnetization components.

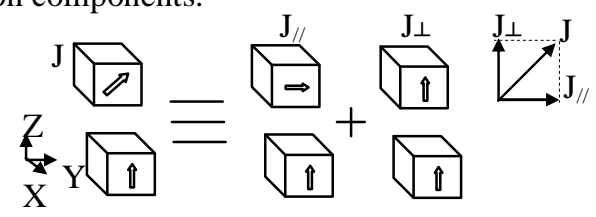

Figure 12 - Inclined case configuration

\section{APPLICATION}

A simple example has been chosen fig. 13 .

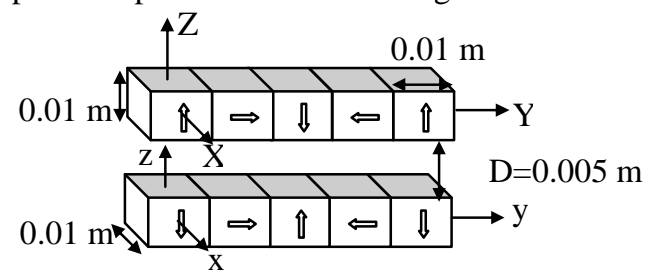

Figure 13 - Four-piece Halbach wiggler system

It's composed of two four-piece Halbach array, one upper the other. The magnetizations parallel to $\mathrm{z}$ axis are inversed for the two arrangements. The $3 \mathrm{D}$ axes are considered at the centre of the first magnets. All the magnetizations are equal and their value is $1 \mathrm{~T}$.

For the first result we consider only the first magnet of the upper four-piece Halbach array Fig. 14, this magnet moves linearly in $\mathrm{Y}$ direction (from $-0,04 \mathrm{~m}$ to $0.08 \mathrm{~m}$ ) - in our model calculation this displacement is considered by imposing the desired value at $\beta$ parameter (see section III-a and III-b)) -

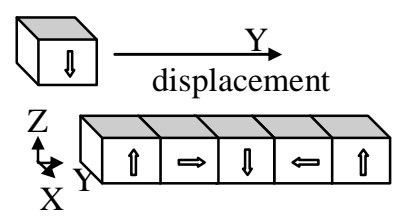

Figure 14 - First magnet above the four-piece Halbach array
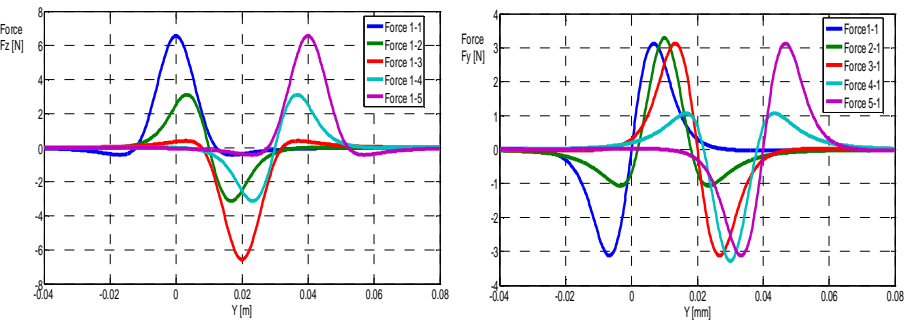

Figure $15-\mathrm{Fz}$ and Fy forces exerted on the upper magnet ( $\mathrm{Z}$ magnetization direction)

Fig. 15 show the calculated forces (Fz and Fy) exerted on the upper magnet by all magnets of the lower Halbach array. For example the curve in blue present the interaction force between the two first magnet noted $1-1$ (when $\beta=0$ the force $\mathrm{Fz}$ is maximal and the corresponding Fy is equal to zero). By the same consideration we can show all interaction forces (from 1 to 5).

If we repeat the same procedure for the second magnet, Fig.16, we obtain also the interaction forces between all magnets Fig. 17, but the difference is the translation of all curves by a quantity $2 \mathrm{~B}=0.01 \mathrm{~m}$ ( $2 \mathrm{~B}$ is the $\mathrm{Y}$ width of the upper magnet, see Figure 3 and 4). It's logical because the centre of all magnets in $\mathrm{Y}$ arrangement is the multiple of the $\mathrm{Y}$ width $(\mathrm{n}(2 \mathrm{~B}))$

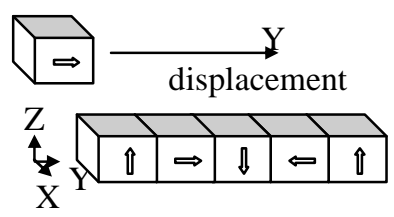

Figure 16 - Second magnet above the four-piece Halbach array
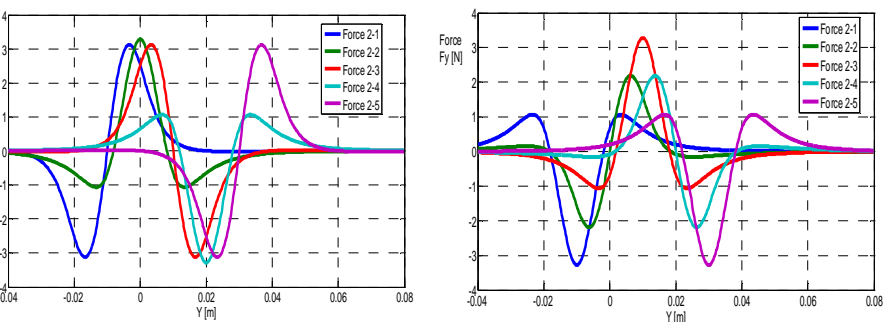

Figure $17-\mathrm{Fz}$ and Fy forces exerted on the upper magnet (Y magnetization direction)

Now, it is interesting to calculate the forces in the three directions which act in the centre of the upper system. For realize this, it is necessary to sum all the forces resulting from the first configuration Halbach and which are exerted on all the magnets of the second.

The total Fz and Fy are presented in Fig. 18 for $\beta=-0.08$ to $0.08 \mathrm{~m}$

For the wiggler system Fig. 13, the global force exerted between the two parts is only a vertical force of $50 \mathrm{~N}$. 

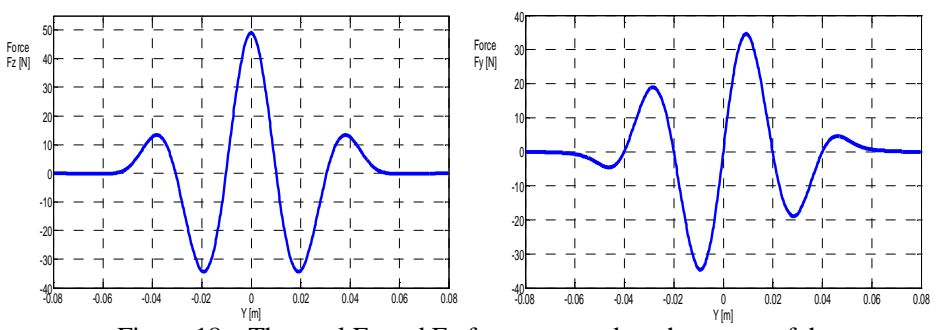

Figure 18 - The total Fz and Fy forces exerted on the centre of the upper four-piece Halbach magnet

We can easily study another simple planar array, it's composed only of parallel magnetization alternatively oriented, this planar array was used as motor by Asawaka [15]. The Asakawa motor is the first kind of permanent magnet planar motors. It is characterized by a large number of permanent magnet cubes, upper the magnets move a rectangular coil and the available forces are varied with the relative position between the coils and the matrix magnet [15-16].

We can study such model, by considering the analogy between the coil and a permanent magnet. A general algorithm is realized for this possibility. An example of $(5 * 6)$ permanent magnets with alternatively opposite (Z) magnetizations directions is shown on Fig. 19. The coil can be considered like a big magnet upper the planar array.

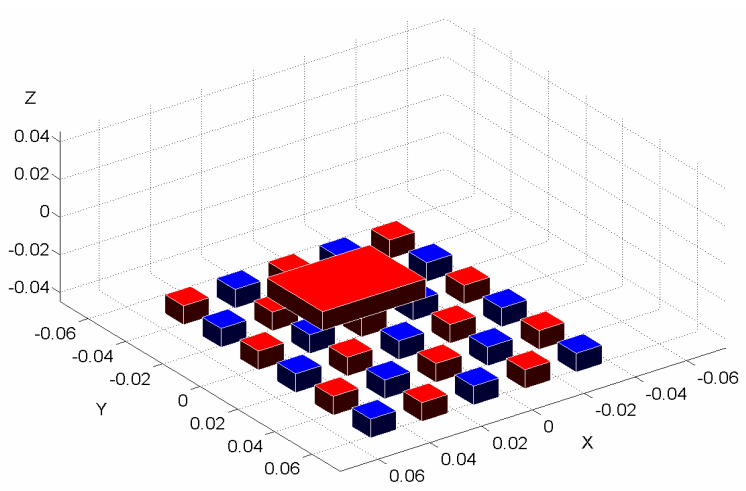

Figure 19 - geometric presentation of $\left(5^{*} 6\right)$ patchwork array

\section{CONCLUSION}

In this paper, The Coulombian approach for 3D interaction forces calculation is shown for cuboïdal permanent magnets with parallel, perpendicular and for any magnetization direction. This approach is perfectly adapted for linear Halbach systems study. The results obtained for the 4-pieces Halbach wiggler system prove that we can calculate the forces exerted on each magnet separately and also determinate the global force on all the Halbach arrays.

By our method the calculation of many magnet systems is possible if we always consider that magnet interactions can be obtained by the superposition of interactions between cuboïdal elements.

\section{REFERENCES}

[1] Jang, S., and Sung, L.: 'Comparison of two types of PM linear synchronous servo and miniature motor with air cored film coil', IEEE Trans. Magn., 2002, 38, (5), pp. 3264-3266

[2] Halbach, K.: 'Application of permanent magnets in accelerators and electron storage rings (invited)', J. Appl. Phys., 1985, 57, (8),pp. 3605-3608

[3] Kratz, R., and Post, R.F.: 'A null-current electro-dynamic levitation system', IEEE Trans. Appl. Supercond., 2002, 12, (1), pp. 930-932

[4] Kartz, R., and Post, R.F.: 'Halbach arrays for maglev applications'.Proc. 6th Int. Symp. on Magnetic Suspension Technology, Turin, Italy, 2001

[5] E. P. Furlani, "Permanent Magnet and Electromechanical Devices; Materials, Analysis and Applications”, Academic,Elsevier, New York, 2001. [6] P. Friend "Magnetic Levitation train technology", progress report, Bradley university, 2004

[7] Trumper, D., Williams, M., and Nguyen, T.: 'Arrays for synchronous machines’. Proc. IEEE Industry Applications Society AnnualMeeting, 1993, Vol. 1, pp. 9-18

[8] Zhu, Z., and Howe, D.: 'Halbach permanent magnet machines and applications: a review', IEE Proc. Electr. Power Appl., 2001, 148, (4),pp. 299-308

[9] M. Marinescu, "Analytische Berechnungen und Modellvorstellungen für Systeme mit Dauermagneten und Eisen", Ph. D., TU Braunschweig, April 1980

[10] J-P. Yonnet, "Etude des Paliers Magnétiques Passifs", Ph.D., INP Grenoble, July 1980

[11] J-P. Yonnet "Analytical Calculation of Magnetic Bearings", Proc of the $5^{\text {th }}$ Int Workshop on Rare Earth Cobalt Permanent Magnets and their Applications, Roanoke, Virginia (USA), June 1981, p. 199 - 216

[12] J-P. Yonnet, S. Hemmerlin, E. Rulliere, G. Lemarquand, "Analytical calculation of permanent magnet couplings", IEEE Trans. on Magnetics, Vol. 29, Nov. 1993, p 2932-2934.

[13] G. Akoun, J-P. Yonnet, "3D analytical calculation of the forces exerted between two cuboïdal magnets", IEEE Trans. Magnetics, MAG 20, n 5 , Sept. 1984, p. 1962-1964.

[14] J-P. Yonnet, "Magneto-mechanical devices", Chap. 9 of "Rare Earth Iron Permanent Magnet" J.M.D. COEY Ed., Oxford University Press, Sept. 1996.

[15] T.Asakawa. "Two Dimensional Precise Positioning Devices for use in semiconductor apparatus". U.S. Patent Office, Patent \# 4535 278, August 1985.

[16] Kim W.j.: «High Precision Planar Magnetic Levitation. Ph.D. thesis, Massachusetts Institute of Technology (1997). 